\title{
UNUSUAL FOX BEHAVIOUR: RABIES EXCLUSION INVESTIGATION
}

Desolie Lovegrove, Illawarra Public Health Unit Keith Hart, Moss Vale Rural Lands Protection Board Tony Ross, Elizabeth Macarthur Agriculture Institute Michael Levy, AIDS / Infectious Diseases Branch. NSW Health Department

$T^{\mathrm{h}}$ he Elizabeth Macarthur Agriculture Institute, the Moss Vale Rural Lands Protection Board and the Illawarra Public Health Unit were involved in an investigation into the possibility that a fox which attacked a group of campers at Kangaroo Valley may have been infected with rabies.

Late in April 1994 a group of about 60 primary school students and four adults from a Sydney school was on a camping trip at Bendeela Ponds, in Kangaroo Valley. One evening a fox approached one of the camping groups and bit through a sleeping bag, lacerating a boy's foot. On the same evening the animal ventured into an opening in a tent in which an instructor was sleeping. The instructor received a laceration to his hand.

First aid was administered immediately and the lacerations covered. The next day the instructor and the student who had received lacerations went to Shoalhaven Hospital for treatment. The lacerations were dressed (no suturing was required) and Adult Diphtheria and Tetanus (ADT) vaccine was administered.

That night the same or a similar animal entered the camp site. The animal approached three boys sleeping on the ground in sleeping bags. This time two boys received scratches to their hands during the encounter. First aid was provided but tetanus boosters were not required.

\section{FOLLOW-UP ACTION}

The incident was reported to the Water Board the next day. Water Board personnel set traps in the area and trapped a fox fitting the description of the animal involved in the attacks. They reported that the fox was behaving in a very agitated and aggressive manner (very unusual behaviour for a trapped fox). They shot the animal and it was sent to Elizabeth Macarthur Agriculture Institute for autopsy.
The autopsy was done under maximum security conditions. The animal was a $6 \mathrm{~kg}$ adolescent fox, apparently healthy except that hair was missing from the tip of its tail to halfway down the tail (probably due to mange). This feature had been noted by some of the witnesses to the attacks and was the main basis of the belief that the animal trapped was the one involved in all biting incidents.

Samples of the brain and other tissues were sent to the Australian Animal Health Laboratory at Geelong to exclude a diagnosis of rabies.

The Illawarra Public Health Unit was consulted about the health risks of everyone who had been in contact with the fox and the fox's secretions - the adult instructor and the four students who had received lacerations from the fox, the Water Board staff who had trapped and shot the fox, the veterinary surgeons from the Elizabeth Macarthur Agriculture Institute and the Rural Lands Protection Board and the laboratory staff from CSIRO Australian Animal Health Laboratory who were involved in the testing.

One of the authors (ML) was consulted on whether postexposure rabies immunisation should be instituted, with counselling for all contacts at risk. After extensive consultation within the NSW Health Department, a decision was made to wait for the preliminary autopsy report on the fox, which was due within 24 hours.

In the meantime, sufficient supplies of rabies immunoglobulin and rabies vaccine were held at the State Vaccine Centre and mechanisms for contact tracing, vaccinating and counselling all contacts were put into place.

The next day the Australian Animal Health Laboratory's preliminary report was received. This showed that the fluorescent antibody tests for rabies conducted on brain stem, cerebellum, hippocampus, cerebrum, optic nerve and salivary gland were all negative. It was then decided that no further public health action would be taken until the final laboratory reports were received. Subsequently all laboratory tests on the fox were reported as negative for rabies, reaffirming that there was no public health risk.

\section{PUBLIC HEALTH EDITORIAL STAFF}

The editor of the Public Health Bulletin is Dr Michael Frommer, Director, Research and Development, NSW Health Department. Dr Lynne Madden is production manager.

The Bulletin aims to provide its readers with population health data and information to motivate effective public health action. Articles, news and comments should be 1,000 words or less in length and include a summary of the key points to be made in the first paragraph. References should be set out using the Vancouver style, the full text of which can be found in British Medical Journal 1988; 296:401-5.

Please submit items in hard copy and on diskette, preferably using WordPerfect, to the editor, NSW Public Health Bulletin, Locked Mail Bag 961, North Sydney 2059. Facsimile (02) 3919029.

Please contact your local Public Health Unit to obtain copies of the NSW Public Health Bulletin. 